\title{
Soft tunic syndrome in the edible ascidian Halocynthia roretzi is caused by a kinetoplastid protist
}

\author{
Akira Kumagai ${ }^{1, *}$, Atsushi Suto ${ }^{1}$, Hiroshi Ito ${ }^{1}$, Toru Tanabe ${ }^{1}$, Jun-Young Song ${ }^{2}$, \\ Shin-Ichi Kitamura ${ }^{2}$, Euichi Hirose ${ }^{3}$, Takashi Kamaishi ${ }^{4}$, Satoshi Miwa ${ }^{5}$ \\ ${ }^{1}$ Miyagi Prefecture Fisheries Technology Institute, Ishinomaki, Miyagi 986-2135, Japan \\ ${ }^{2}$ Centre for Marine Environmental Studies (CMES), Ehime University, Matsuyama, Ehime 790-8577, Japan \\ ${ }^{3}$ Department of Chemistry, Biology and Marine Science, University of the Ryukyus, Nishihara, Okinawa 903-0213, Japan \\ ${ }^{4}$ National Research Institute of Aquaculture, Fisheries Research Agency, Minami-ise, Mie 516-0193, Japan \\ ${ }^{5}$ Inland Station, National Research Institute of Aquaculture, Fisheries Research Agency, Tamaki, Mie 519-0423, Japan
}

\begin{abstract}
An etiological study was conducted to clarify whether the flagellate-like cells found in histological preparations of the tunic of diseased Halocynthia roretzi (Drasche) were the causative agent of soft tunic syndrome in this ascidian. When pieces of softened diseased tunic were incubated overnight in sterile seawater, live flagellated cells, which were actively swimming in the seawater, were observed in 47 out of 61 diseased ascidians $(77 \%)$, but not in moribund or abnormal individuals with normal tunics $(n=36)$ nor in healthy animals $(n=19)$. The flagellate was morphologically very similar to those observed in histological sections of the diseased tunic. By contrast, flagellates were not found in tunic pieces of healthy, moribund, and abnormal individuals that did not exhibit softening of the tunic. Light and electron microscopy revealed that the flagellate has polykinetoplastic mitochondria with discoidal cristae. The cytomorphologies of the flagellate were the same as those of the flagellate-like cells in the diseased tunic. We cultured the flagellate from the softened tunic in vitro and confirmed that the tunics of healthy ascidians, which were immersion-challenged with suspensions of the subcultured flagellates, became softened $17 \mathrm{~d}$ after exposure, including the final $12 \mathrm{~d}$ in aerated, running seawater. The occurrence of flagellates was also confirmed by incubating pieces of soft tunic from experimentally infected animals in seawater overnight. These results indicate that the flagellate is the causative agent of soft tunic syndrome.
\end{abstract}

KEY WORDS: Ascidian · Halocynthia roretzi $\cdot$ Soft tunic syndrome $\cdot$ Causative agent $\cdot$ Kinetoplastid protist · Flagellate

Resale or republication not permitted without written consent of the publisher

\section{INTRODUCTION}

In Korea, mass mortality of the cultured ascidian Halocynthia roretzi (Drasche) from a disease of unknown etiology, has been a serious problem since 1995 (Jung et al. 2001). The tunics of affected ascidians are physically very soft, and the disease has been called 'tunic softness syndrome' (Hur et al. 2006) or 'soft tunic syndrome' (Hirose et al. 2009). In February 2007, outbreaks of soft tunic syndrome occurred in cultured ascidians in Miyagi Prefecture, Japan, in the areas where
Korean spat had been introduced in 2004 and 2006. The disease has re-occurred every year, and the number of affected areas has been increasing. The disease is a serious problem in the aquaculture of ascidians, and hence, identification of the cause of the disease is urgently needed to control the epizootic (Kumagai et al. 2010).

Prominent histopathological changes were found in the tunics of diseased ascidians, but not in the internal organs (Hirose et al. 2009, Kitamura et al. 2010, Kumagai et al. 2010). Kumagai et al. (2010) demonstrated 
that the disease is transmissible by experimental infection in which pieces of softened tunics were immersed in the rearing seawater of healthy animals. The result indicated that the causative agent was released from the affected animals, became waterborne, and infected healthy ascidians. Histology showed flagellate-like cells $(10-14 \times 2-3 \mu \mathrm{m})$ in the tunics of spontaneously or experimentally diseased ascidians, but not in the apparently healthy animals (Kumagai et al. 2010). In situ hybridization using probes for the ascidian 18S rRNA gene did not result in a signal for the gene in the flagellate-like cells, indicating the possibility that these cells are not ascidian cells but are a distinct organism (Kumagai et al. 2010). In addition, neither bacteria nor virus-like particles were observed in affected ascidians (Hirose et al. 2009, Kitamura et al. 2010, Kumagai et al. 2010). The results of the physical properties of the causative agent are consistent with the hypothesis that the flagellate-like cells are a flagellated protist, and the causative agent of soft tunic syndrome; the tunics of affected animals lost infectivity when frozen or homogenized, and the presumed infectious agent could pass through a $5.0 \mu \mathrm{m}$ membrane filter, but not a $0.45 \mu \mathrm{m}$ filter (Kumagai et al. 2010).

In the present study, we found flagellates in the seawater in which pieces of softened tunics of spontaneously diseased ascidians were immersed. Morphological characteristics of the flagellated protist were studied by light and electron microscopy and compared with those in the diseased tunic. Furthermore, we cultured the flagellate in vitro, and confirmed by experimental infections using a pure culture of the flagellate that the flagellate is the causative agent of soft tunic syndrome.

\section{MATERIALS AND METHODS}

Flagellate examination. Individuals of Halocynthia roretzi were sampled from 11 farming sites in Miyagi Prefecture, Japan. Diseased ascidians ( $\mathrm{n}=2$ to 8 per site, 61 in total) comprising 34 animals with severely softened tunics, which were categorized as Grade 3 and Grade 4 specimens according to the criteria of Kitamura et al. (2010), and 27 animals with mildly softened tunics categorized as Grade 2, were sampled during February to August of 2009 from 11 farming sites. For comparison, moribund or abnormal individuals ( $\mathrm{n}=$ 36) that had a rigid tunic, and were hence thought to be affected by factors other than soft tunic syndrome, were sampled from 6 sites in the same period. These samples included animals that had deteriorated appendages for attachment to the substratum, and animals whose tunics were hard, but discolored and lacked elasticity. Apparently healthy individuals ( $\mathrm{n}=$
18, Grade 0) were also sampled from 3 sites where the disease had not occurred.

Each ascidian tunic (5 to $10 \mathrm{~g} ; \mathrm{n}=115$ ) was cut into small pieces (approximately $5 \times 1 \mathrm{~cm}$ ), and individually put into a polyethylene bag $(8.5 \times 6 \mathrm{~cm})$ containing $20 \mathrm{ml}$ of sterilized seawater, and incubated at $15^{\circ} \mathrm{C}$ overnight. After incubation, $100 \mu \mathrm{l}$ of the seawater from each bag was put on a glass slide. A light microscope was used to examine the seawater for flagellates that morphologically resembled the flagellate-like cells observed histologically in the tunics of diseased ascidians.

Softened tunic $(20 \mathrm{~g})$ of an infected ascidian was cut into small pieces $(5 \times 1 \mathrm{~cm})$, immersed in $100 \mathrm{ml}$ sterilized seawater at $15^{\circ} \mathrm{C}$ overnight. After incubation, the seawater was passed through a $1 \mu$ m nylon mesh (NYTAL) to remove other organisms to the greatest extent possible. The flagellate found in the seawater incubated with affected tunic pieces was fixed in $2.5 \%$ glutaraldehyde-seawater. After a brief rinse with filtered seawater, the DNA of the flagellate was stained with DAPI (4',6-diamidino-2-phenylindole). The fixed flagellated cells were examined with a light microscope equipped with differential interference contrast (DIC) optics and epi-fluorescence for UV excitation. Several DIC photomicrographs were combined to increase the depth of field by using the image post-processing software Helicon Focus Pro 3.79 (Helicon Soft).

We also conducted histopathological observations for flagellate-like cells in the tunics of the 61 diseased ascidians according to the method of Kumagai et al. (2010). Two or more tunic pieces were cut from each ascidian and fixed in Davidson's fixative (Bell \& Lightner 1988) overnight. Tissues were then dehydrated in an ethanol series and embedded in paraffin wax via xylene. Sections were cut at $3 \mu \mathrm{m}$ and stained with Mayer's hematoxylin and eosin (H\&E).

The tunics of diseased ascidians ( $\mathrm{n}=11$, Grades 2 to 4) sampled from a farming site in Korea in March 2010 were also used for protist observations.

Electron microscopy of the flagellate. The flagellated cells that occurred in seawater-incubation with the diseased tunic were fixed in $2.5 \%$ glutaraldehydeseawater and concentrated by centrifugation $(2000 \times g$, $10 \mathrm{~min})$. After a brief rinse with $0.45 \mathrm{M}$ sucrose buffered with $0.1 \mathrm{M}$ sodium cacodylate ( $\mathrm{pH} 7.4$ ), a portion of the precipitate was post-fixed with $1 \%$ osmium tetroxide-0.1 $\mathrm{M}$ cacodylate for $2 \mathrm{~h}$ on ice, and then dehydrated through an ethanol series. The flagellates were cleared with $n$-butyl glycidyl ether and embedded in epoxy resin. Thin sections were stained with lead citrate and uranyl acetate and examined with a JEOL JEM-1011 transmission electron microscope (TEM) at $80 \mathrm{kV}$. The other portion of the precipitate was dehydrated through an ethanol series, immersed 
in $t$-butanol, and freeze-dried. The dried specimens were sputter-coated with gold-palladium and examined with a JEOL JSM-6060LV scanning electron microscope (SEM) at $15 \mathrm{kV}$.

Diseased individuals (Grade 4) of Halocynthia roretzi were collected in June 2009 at an aquaculture site in Miyagi Prefecture, Japan. Several tunic pieces (ca. $1 \times$ $2 \times 2 \mathrm{~mm}$ ) were cut from the diseased individuals. The specimens were fixed in $2.5 \%$ glutaraldehyde- $0.45 \mathrm{M}$ sucrose-0.2 M cacodylate ( $\mathrm{pH} 7.4$ ) and processed for TEM observation as described above.

In vitro cultivation of the flagellate. The tunic $(2.1 \mathrm{~g})$ of a diseased ascidian (Grade 4), sampled in December 2009 from a farming site in Miyagi Prefecture, was cut into 3 small pieces (approximately $1 \times 1 \mathrm{~cm}$ ) and washed 3 times in a Petri dish with Eagle's minimum essential medium (MEM) containing $0.3 \mathrm{mg} \mathrm{ml}^{-1}$ of vancomycin (Nacalai Tesque). The 3 tunic pieces were then incubated in $20 \mathrm{ml}$ of MEM containing $0.1 \mathrm{mg}$ $\mathrm{ml}^{-1}$ of vancomycin at $15^{\circ} \mathrm{C}$ for $12 \mathrm{~h}$ to allow flagellates to migrate into the medium. The sample was centrifuged at $100 \times g$ for $3 \mathrm{~min}$ to spin down the tunic pieces.

The 5 or $20 \mu$ l of supernatant containing flagellates was inoculated into $1 \mathrm{ml}$ of either $100,90,50$, or $10 \%$ (v/v) culture medium diluted with artificial seawater (New Marin Merit, Matsuda) in 24-well plates, and cultured at $15^{\circ} \mathrm{C}$ for 5 to $10 \mathrm{~d}$ to compare growth of the flagellate. The $100 \%$ culture medium comprised MEM, heat-inactivated fetal bovine serum $(25 \%$ v/v FBS, Invitrogen) and $20 \mathrm{mM}$ sodium bicarbonate. In addition, we tried to use a heat-inactivated horse serum (Invitrogen) at the above concentrations instead of FBS. All media included 5 mM HEPES, 2 mM L-glutamine and Penicillin-Streptomycin Mixed Solution (1\% v/v; Nacalai Tesque). The cultured flagellate was observed daily. The flagellate showing the fastest growth in the optimum medium was subcultured in maintenance medium $(10 \% \mathrm{w} / \mathrm{v}$ of MEM , $2.5 \% \mathrm{v} / \mathrm{v}$ of FBS, 5 mM HEPES, 2 mM L-glutamine, 2 mM sodium bicarbonate and $1 \% \mathrm{v} / \mathrm{v}$ of Penicillin-Streptomycin Mixed Solution prepared in artificial seawater) at least 10 times in $75 \mathrm{~cm}^{2}$ culture flasks. Finally, we confirmed that the culture fluid was free from other protozoan contamination using an inverted microscope, and free from bacterial contamination by inoculation into brain heart infusion broth (Becton Dickinson) and Marine broth 2216 (Becton Dickinson), before using it for experimental infections.

Infection trial. An infection trial was carried out using the 14th passage flagellate at the Miyagi Prefecture Fisheries Technology Institute. Seawater used for the experiment was pumped from offshore of the laboratory and filtered through a sand filter before flowing into the experimental aquaria. The rearing water temperature ranged from 13 to $17^{\circ} \mathrm{C}$.
The flagellate was subcultured in $10 \mathrm{ml}$ of maintenance medium at $15^{\circ} \mathrm{C}$ for $7 \mathrm{~d}$. After the subculture, $7,0.7,0.07,0.007$ or $0.0007 \mathrm{ml}$ of the flagellate cell suspension $\left(1.7 \times 10^{6}\right.$ cell $\left.\mathrm{ml}^{-1}\right)$ was added to 5 aquaria (25 1). The concentration of the flagellate cell suspension was determined using Burker-Turk hemacytometers before dilution. Each of the aquaria contained $12 \mathrm{l}$ of seawater and 12 healthy, 1 yr old ascidians (90 g body weight) obtained from a farming site where the disease had not been observed. The final nominal concentrations of the flagellate in the aquaria were $1000,100,10,1$ or $0.1 \mathrm{cell} \mathrm{ml}^{-1}$. The seawater was not changed, although aerated, for the first $5 \mathrm{~d}$ of the experiment. Six days after the start of the experiment, new seawater was introduced into the experimental aquaria, and thereafter, all ascidians were reared in 201 of aerated, running seawater. For the control, 12 healthy animals were similarly reared in another aquarium, but without adding the flagellate cell suspension. The experiment was conducted for $30 \mathrm{~d}$, and the softening of the tunics was monitored by touching the ascidians every $2 \mathrm{~d}$. When dead ascidians were found, they were removed from the aquaria. The small pieces of tunic of all the dead ascidians ( $\mathrm{n}=22$ in total) were immersed in seawater at $15^{\circ} \mathrm{C}$ overnight and the occurrence of the flagellate was checked for each individual ascidian as described in 'Flagellate examination'. Pieces of the tunics of 5 out of 22 dead ascidians were fixed in Davidson's solution for histopathological observations.

\section{RESULTS}

\section{Occurrence of flagellated cells}

In the histopathological examination of the tunics of diseased ascidians, the flagellate-like cells were found in all animals with severely softened tunics, and 93\% of mildly affected animals (Table 1). In the seawater incubated with tunic pieces of diseased ascidians, flagellated cells were found in $85 \%$ of severely softened tunics, and $67 \%$ of mildly affected animals (Table 1). The flagellates moved actively in seawater by using 2 flagella, changed to amoeboid form when they veered, and passed through a $1 \mu \mathrm{m}$ nylon mesh. The concentration of the flagellates in seawater reached over $10^{6} \mathrm{ml}^{-1}$ when the tunics of heavily diseased ascidians were incubated. No flagellates were found in seawater incubated with tunic pieces from apparently healthy individuals $(\mathrm{n}=18)$, or with tunic pieces from moribund or abnormal individuals $(\mathrm{n}=36)$ that were thought to be affected by factors other than the soft tunic syndrome (Table 1). Apparently identical flagellates were also observed in seawater incubated with tunic pieces from 9 of 11 affected animals (82\%) sampled in Korea. 
Table 1. Halocynthia roretzi. Results of flagellate examination of ascidian tunics. Tunics were examined for flagellates by histology. NE: not examined

\begin{tabular}{|lccc|}
\hline Sample & $\begin{array}{c}\text { No. of ascidians } \\
\text { examined }\end{array}$ & $\begin{array}{c}\text { No. (\%) positive for flagellate(-like) cells } \\
\text { In tunics }\end{array}$ & $\begin{array}{c}\text { In seawater } \\
\text { Ascidians with severely softened tunics }\end{array}$ \\
Ascidians with mildly softened tunics & 34 & $34(100)$ & $29(85)$ \\
Moribund or abnormal ascidians without softened tunics & 27 & $25(93)$ & $18(67)$ \\
Healthy ascidians & 36 & NE & $0(0)$ \\
\hline
\end{tabular}

\section{Microscopic characterization of the flagellate}

The flagellate was a fusiform cell with 2 flagella, and the cell was 10 to $13 \mu \mathrm{m}$ long excluding the flagella (Fig. 1). The cell contained round granules 0.5 to $1 \mu \mathrm{m}$ in diameter (black arrowheads in Fig. 1A,B), and DAPI fluorescence was found as several dots in the cytoplasm (Fig. 1C). Both flagella originated from cytoplasm close to the anterior end of the cell: one flagellum extended anteriorly (i.e. anterior flagellum) and the other posteriorly (i.e. posterior flagellum). The posterior flagellum was often located in a longitudinal furrow along the entire cell body (Fig. 1E). The cell surface appeared smooth when viewed by SEM, indicating the absence of scales (Fig. 1D,E).

Transmission electron microscopy showed that the anterior and posterior flagella emerged from the flagellar pocket at the antero-lateral end of the cell (Fig. 2A). A nucleus was usually situated in the middle part of the cell. The cell surface was not covered by a lorica or scales. The cytoplasm contained mitochondria with discoidal cristae and kinetoplasts (Fig. 2B). Several kinetoplasts were often found in a mitochondrion. There were 3 types of round granules: oil granules, glycosome-like granules, and heterogenous granules with striations (Fig. 2B,C). Prominent phagosomes were not found in the present observation.
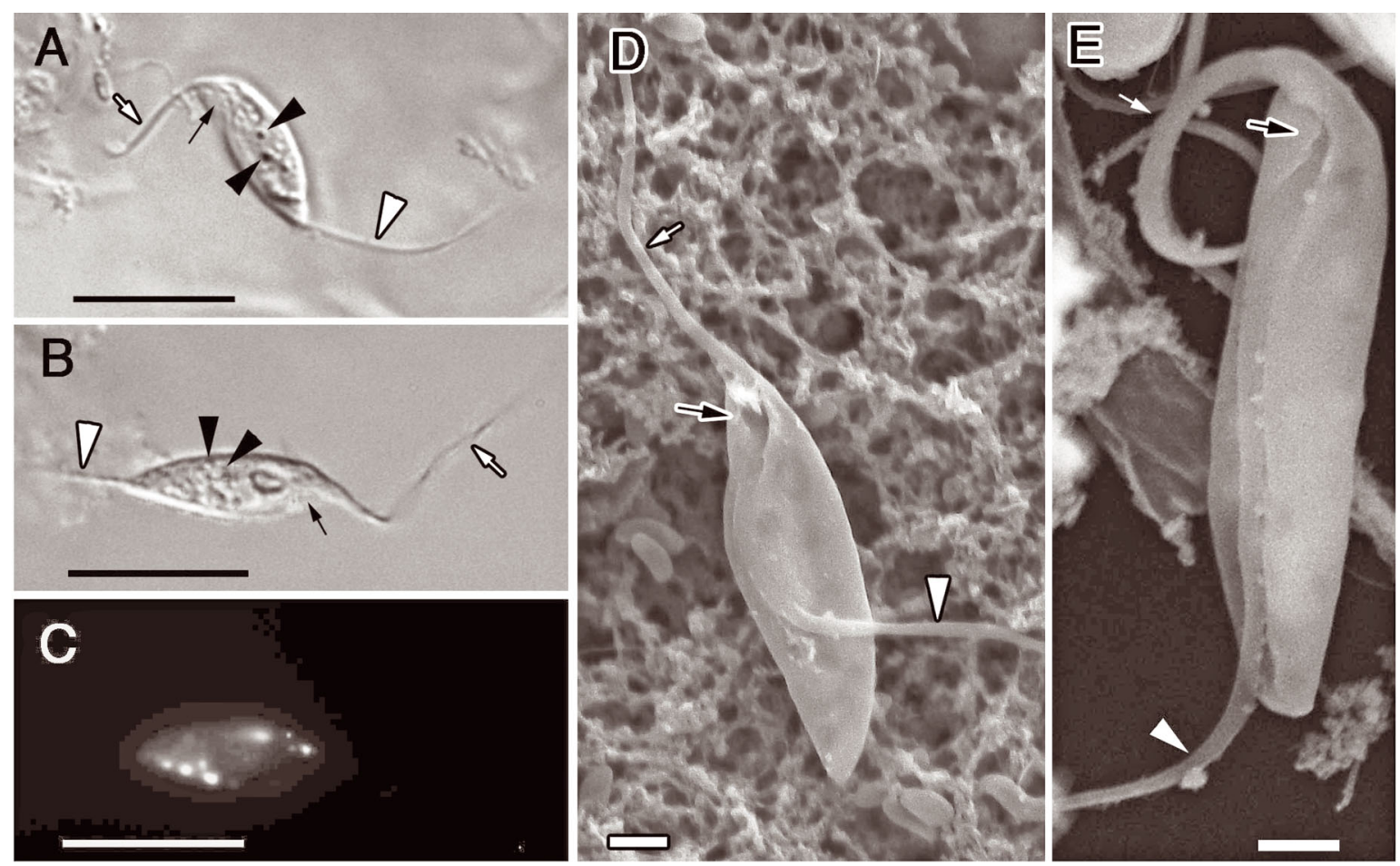

Fig. 1. Halocynthia roretzi. Flagellate in seawater incubated with the tunics of a diseased ascidian. (A-C) Whole-mount photomicrographs: $(A, B)$ differential interference contrast; (C) DAPI fluorescence. (D,E) SEM. (B) and (C) show the same specimen. Black arrows $(A, B, D, E)$ : emerging point of the 2 flagella; white arrows $(A, B, D, E)$ : anterior flagellum; white arrowheads $(A, B, D, E)$ : posterior flagellum; black arrowheads $(A, B)$ : round granules. Scale bars $=(A-C) 10 \mu m,(D, E) 1 \mu m$ 


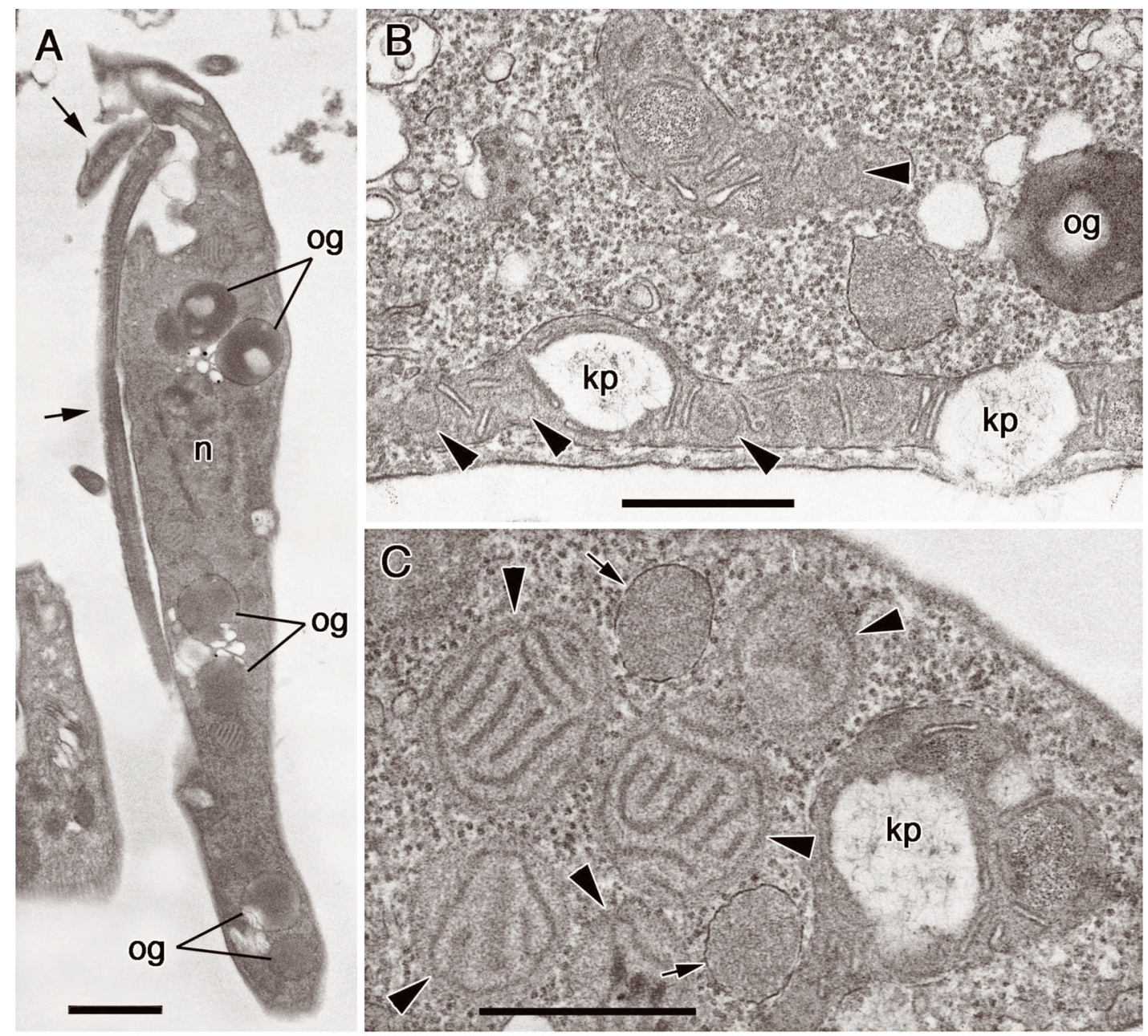

Fig. 2. Halocynthia roretzi. Flagellate in seawater incubated with the tunics of a diseased ascidian (TEM). (A) Semi-longitudinal section of the flagellate, showing anterior and posterior flagella (arrows) emerging from the antero-lateral end of the cell. n: nucleus. (B) Enlargement of mitochondria with discoidal cristae (arrowheads) and kinetoplasts (kp). (C) Glycosome-like

granules (arrows) and round granules with striations (arrowheads). og: oil granules. Scale bars $=(A) 1 \mu \mathrm{m},(\mathrm{B}, \mathrm{C}) 0.5 \mu \mathrm{m}$

\section{Microscopic characterization of the flagellate in the diseased tunic}

The flagellated cells were found exclusively in the tunic of diseased individuals. They often formed a loose aggregate in the tunic matrix, where the tunic fibers were sparse and disintegrated (Fig. 3A). Ascidian cells around the flagellated cells were often degenerative, and cellular debris was also found. However, no direct contact was observed between the flagellate and the host cells. Since the flagellated cells had neither lorica nor scales, it was often difficult to discriminate them morphologically from the ascidian cells. The most distinctive feature of the flagellated cells was the presence of the flagella. Both flagella were found in some sections of the flagellated cells (Fig. 3B). However, the flagella were not readily found in many fla- gellate-like cells in thin sections, and some oblique sections of a flagellum-like structure were indistinguishable from pseudopodia. At higher magnification, these flagellated cells often had oil granules, striated granules, and kinetoplasts that were found in the flagellated cells occurring in seawater incubated with the diseased tunic pieces (Fig. 3C,D; see also Fig. 2).

\section{Growth of the flagellate in culture in vitro}

Optimum growth of the flagellates was in the $10 \%$ medium. The maximum cell density, $1.5 \times 10^{6} \mathrm{cells} \mathrm{ml}^{-1}$, was observed at $8 \mathrm{~d}$ post inoculation in the medium, whereas little or no growth was observed in the other media. Additionally, no growth was observed when horse serum was used as an alternative to FBS. 


\section{Infection trial}

The tunics of the healthy ascidians that were immersion-challenged with suspensions of the flagellate at concentrations higher than 10 cells ml ${ }^{-1}$ became softened, and they were considered to have developed soft tunic syndrome. The higher the flagellate concen- tration, the higher the prevalence of the disease (Table 2). Once tunics became softened, the ascidians did not recover and eventually died 5 to $8 \mathrm{~d}$ after the softening of the tunics was noticed. In microscopic observations of the seawater incubated with softened tunic of 22 experimentally diseased ascidians, the same flagellate was observed in all samples as in the
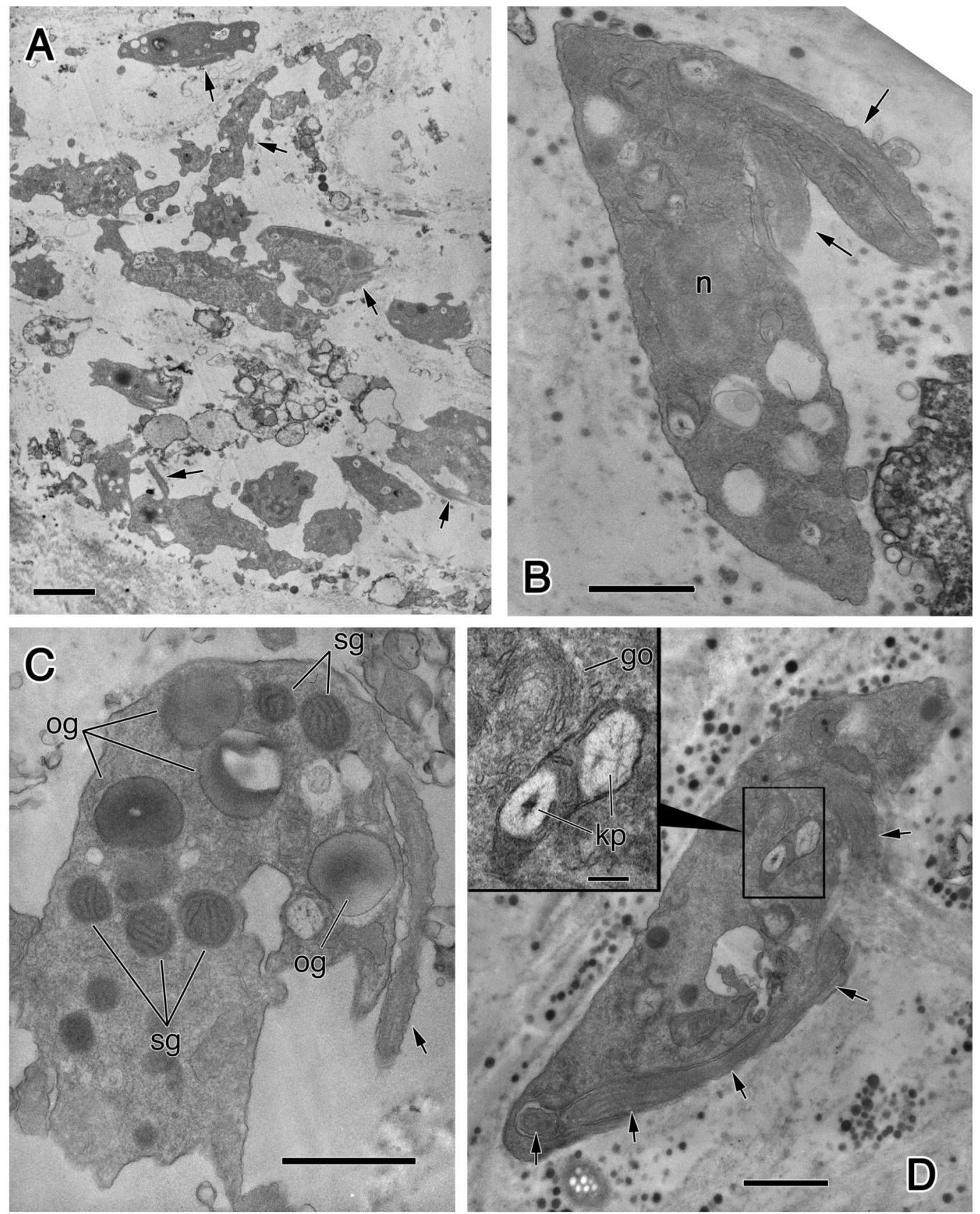

Fig. 3. Halocynthia roretzi. Flagellated cells in the tunic of a diseased ascidian (TEM). (A) A loose aggregate of flagellated cells. Flagellum-like structures are found with some cells (arrows). (B) Two flagella (arrows) extend from the antero-lateral part of the cell; n: nucleus. (C) Cytoplasm contains oil granules (og) and striated granules (sg); arrow: flagellum. (D) Posterior flagellum (arrows) is partly embedded in the furrow. (D, inset) Golgi body (go) and a mitochondrion with kinetoplasts (kp). Scale bars =

(A) $2 \mu \mathrm{m},(\mathrm{B}-\mathrm{D}) 1 \mu \mathrm{m},(\mathrm{D}$, inset) $0.2 \mu \mathrm{m}$ 
Table 2. Halocynthia roretzi. Results of bath infection trial. Appearance of clinical signs was measured as the number of days after the start of the experiment when the softening of the tunic was first detected. conc.: concentration

\begin{tabular}{|lcc|}
\hline $\begin{array}{l}\text { Flagellate conc. } \\
(\text { no. ml }\end{array}$ & $\begin{array}{c}\text { Appearance of } \\
\text { clinical signs (d) }\end{array}$ & $\begin{array}{c}\text { No. of dead/total } \\
\text { no. of ascidians }\end{array}$ \\
\hline 1000 & 17 & $11 / 12$ \\
100 & 17 & $10 / 12$ \\
10 & 23 & $1 / 12$ \\
1 & - & $0 / 12$ \\
0.1 & - & $0 / 12$ \\
0 & - & $0 / 12$ \\
\hline
\end{tabular}

infected ascidians from the field. Histological observations of 5 experimentally diseased tunics showed that the arrangement of tunic fibers was markedly disturbed, and that many flagellated cells were present (Fig. 4).

\section{DISCUSSION}

In this study, the flagellate occurred specifically in the seawater incubated with the diseased ascidian tunics in which the flagellate-like cells were
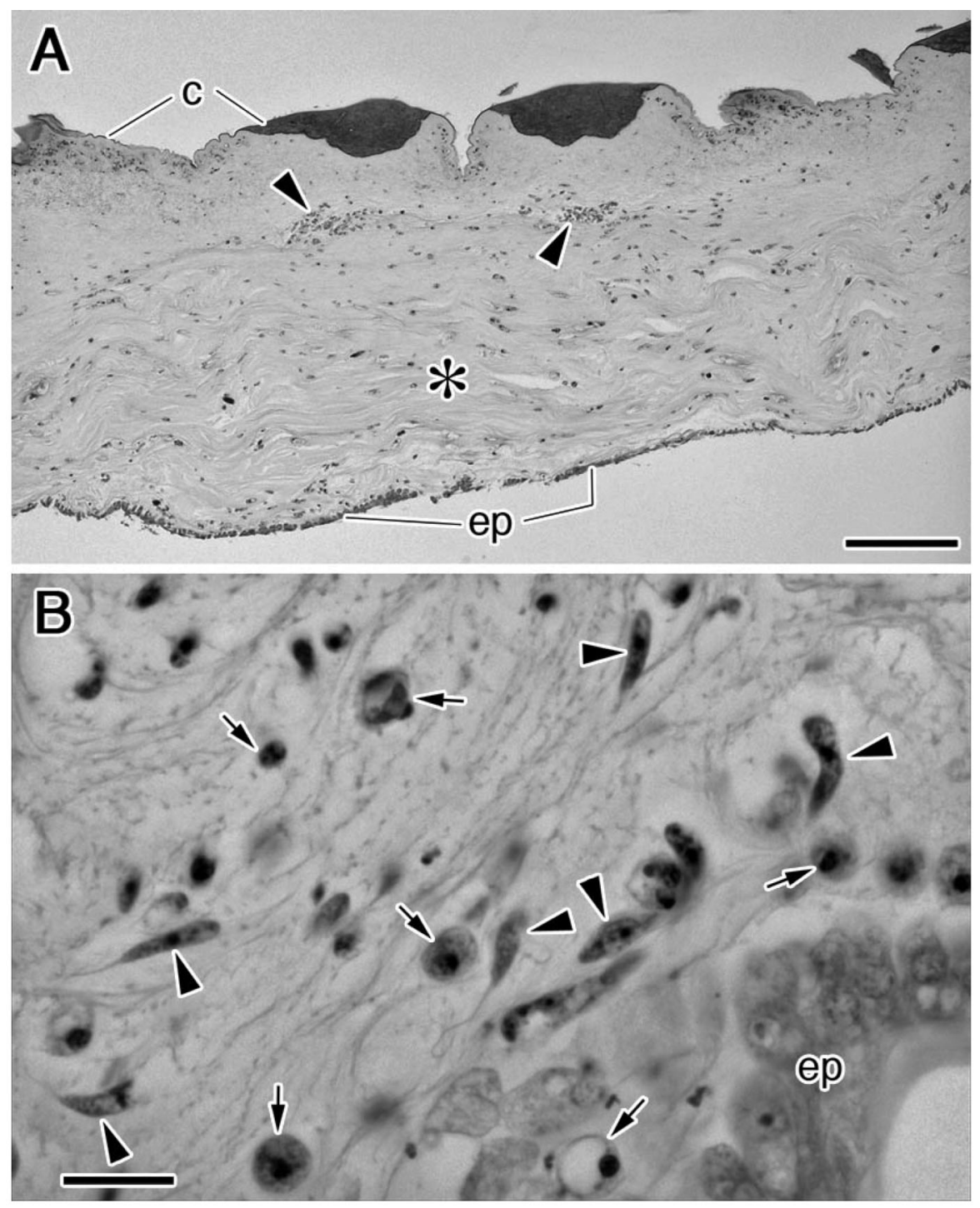

Fig. 4. Halocynthia roretzi. Tunic of experimentally infected ascidians showing disease signs (histopathological sections stained with H\&E). (A) Cross section of the diseased tunic containing clusters of flagellated cells (arrowheads); arrangement of tunic fibers is markedly disturbed (*). c: tunic cuticle; ep: epidermis. (B) Flagellated cells (arrowheads) and ascidian cells (arrows) within the tunic. Scale bars $=(A) 100 \mu \mathrm{m}$, (B) $10 \mu \mathrm{m}$ 
histopathologically observed. The flagellate was not observed in seawater incubated with apparently healthy ascidians, or with the moribund and abnormal individuals that were thought to be affected by factors other than soft tunic syndrome. In contrast, in situ hybridization using probes for the 18S rRNA and $\beta$-tubulin gene sequences of the flagellate which occurred in the incubation seawater, revealed that the flagellates are identical to the flagellate-like cells in diseased tunics (T. Kamaishi et al. unpubl. data). In addition, we succeeded in cultivating the flagellates in $10 \%$ MEM-25 diluted with artificial seawater and confirmed that the tunics of the healthy ascidians that were immersion-challenged with suspensions of the purely subcultured flagellates became softened. The prevalence of the disease in the experimental infection was related to the flagellate concentration in a dosedependent manner. The occurrence of the flagellate in the experimentally infected ascidians was confirmed by incubating pieces of the experimentally infected tunics in seawater. The presence of flagellated cells in the tunic was also confirmed histopathologically. These results indicate that the flagellate is the causative agent of soft tunic syndrome.

The flagellate was observed in seawater incubated with only 18 out of 27 mildly affected ascidians, but found in 29 of the 34 animals that had markedly soft tunics. The density of flagellates in seawater incubated with the heavily diseased ascidian tunic reached over $10^{6} \mathrm{ml}^{-1}$. There seems to be a positive correlation between the density of the flagellated cells in seawater and the severity of the disease. Thus, the soft tunic syndrome can be diagnosed by confirming the occurrence of flagellated cells in seawater incubated with the diseased ascidian tunics. This method is not as sensitive as histopathological observations, but is more convenient, because it is easy to find the swimming flagellated cells.

The flagellated protist had a single nucleus, 2 flagella, and polykinetoplastic mitochondria with discoidal cristae. Since the kinetoplast is a dense DNAcontaining granule, several dots in the cytoplasm stained with DAPI were thought to be the multiple kinetoplasts in mitochondria and the single nucleus. Following the classification of Vickerman (2000), the presence of several kinetoplasts and 2 (anterior and posterior) flagella of the flagellate found in the seawater incubated with affected tunic pieces, indicate that it is a member of the family Bodonidae (Euglenozoa: Kinetoplastea). The presence of glycosome-like granules and a posterior flagellum attached to the cell body are also characteristics of some bodonid species. Recently Moreira et al. (2004) revised the classification of the class Kinetoplastea, proposing a molecular phylogeny based on 18S rRNA sequences. According to this updated classification, the present flagellate probably belongs to the order Neobodonida (Kinetoplastea: Metakinetoplastea), because the flagellate has polykinetoplastic mitochondria and 2 flagella with a posterior flagellum attached to the body. This taxonomic consideration based on these microscopic features is consistent with the molecular phylogeny inferred from $18 \mathrm{~S}$ rRNA and $\beta$-tubulin gene sequences of this flagellate (T. Kamaishi et al. unpubl. data). Besides these kinetoplastean characters, the flagellate has striated granules that have never been reported from other flagellates. Thus, the present species is likely a hitherto undescribed species of Neobodonida, and a taxonomic description should be undertaken based on more detailed ultrastructure and molecular data.

Although neither protists nor bacteria were observed in diseased tunics in previous ultrastructural studies (Hirose et al. 2009, Kitamura et al. 2010), flagellated cells were found in diseased tunics in this study. The flagellate in tunics also had polykinetoplastic mitochondria and striated granules, indicating that this kinetoplastid is identical to that found in seawater incubated with diseased tunics. Except for the presence of flagella and other characteristic organelles, such as kinetoplasts or granules with unique features, the flagellate in diseased tunics has some morphological features similar to those of ascidian tunic cells observed by TEM. Moreover, the distribution of the flagellate was very uneven in the histological observations (Kumagai et al. 2010). TEM sections are too thin to observe the whole cell shape of the flagellate, and the observable area in TEM specimens is much smaller than that in paraffin wax sections. These are possible reasons why the kinetoplastid was overlooked in previous ultrastructural observations. For inspection of the disease, histopathology would be more convenient and sensitive than TEM. DAPI-fluorescence microscopy is also useful to discriminate this polykinetoplastic flagellate from other protists, because the kinetoplasts of the flagellate are visualized as multiple dots in the cytoplasm.

The presence of many oil granules in the cytoplasm might be a sign of well-nourished protists, but how and on what the flagellates feed has not been studied. This would be one of the key questions to understand the mechanism of tunic softening. Prominent phagosomes were not found in the flagellate cytoplasm, suggesting they do not ingest food via phagocytosis. Instead, the flagellate might simply absorb soluble materials from the tunic. This is further supported by the fact that the flagellate could propagate in the medium without bacteria. In the tunic, there appeared to be no direct interactions between the flagellated cells and the host cells. Thus, the flagellate may be able to evade the innate immune system of the ascidians. 
In conclusion, the flagellate isolated from the softened tunics of infected ascidians from the field fulfills Koch's postulates as the etiological agent of soft tunic syndrome. Based on the microscopic characteristics, the flagellate is thought to be a kinetoplastid belonging to the order Neobodonia (Euglenozoa: Kinetoplastea). The disease has re-occurred every year in farming sites where an outbreak of the disease occurs once, and the number of affected areas has been increasing (Kumagai et al. 2010). Therefore, the flagellate seems to have become established in many Japanese ascidian farming areas. It is still unclear whether the flagellate is an obligatory or facultative parasite and whether it has reservoir hosts other than the ascidian Halocynthia roretzi. It is also unknown whether the flagellate has a free-living dispersive phase in the life cycle, and whether it is present from September to November when the disease subsides. Further study on the biology of the flagellate is needed to control this epizootic.

Acknowledgements. We thank Professor J. T. Sung (Gyeongsang National University) and Professor B. D. Choi (Gyeongsang National University) for their help in sampling diseased ascidians in Korea. Thanks also to Dr. T. Nakayama (University of Tsukuba) for valuable advice on the taxonomy of kinetoplastids. This study was supported by a grant from the Ministry of Agriculture, Forestry, and Fisheries of Japan.

Editorial responsibility: Eugene Burreson, Gloucester Point, Virginia, USA

\section{LITERATURE CITED}

Bell TA, Lightner DV (1988) A handbook of normal penaeid shrimp histology. Allen Press, Lawrence, KS

- Hirose E, Ohtake S, Azumi K (2009) Morphological characterization of the tunic in the edible ascidian Halocynthia roretzi (Drasche), with remarks on 'soft tunic syndrome' in aquaculture. J Fish Dis 32:433-445

Hur YB, Park JH, Han HK, Choi HS, Kyun MK, Yun HD (2006) Mass mortality of the cultured sea squirts Halocynthia roretzi in Korea. In: Abstracts of the International Workshop on Summer Mortality of Marine Shellfish, Busan. Pusan National University, Busan, p 41

Jung SJ, Oh MJ, Date T, Suzuki S (2001) Isolation of marine birnavirus from sea squirts Halocynthia roretzi. In: Sawada H, Yokosawa H, Lambert CC (eds) The biology of ascidians. Springer-Verlag, Tokyo, p 436-441

Kitamura SI, Ohtake SI, Song JY, Jung SJ and others (2010) Tunic morphology and viral surveillance in diseased Korean ascidians: soft tunic syndrome in the edible ascidian, Halocynthia roretzi (Drasche), in aquaculture. J Fish Dis 33:153-160

> Kumagai A, Suto A, Ito H, Tanabe T, Takahashi K, Kamaishi T, Miwa S (2010) Mass mortality of cultured ascidians Halocynthia roretzi associated with softening of the tunic and flagellate-like cells. Dis Aquat Org 90:223-234

Moreira D, Lopez-Garcia P, Vickerman K (2004) An updated view of kinetoplastid phylogeny using environmental sequences and a closer outgroup: proposal for a new classification of the class Kinetoplastea. Int J Syst Evol Microbiol 54:1861-1875

Vickerman K (2000) Order Kinetoplastea. In: Lee JJ, Leedale GF, Bradbury P (eds) An illustrated guide to the protozoa: organisms traditionally referred to as protoza, or newly discovered groups, 2nd edn. Society of Protozoologists, Lawrence, KS, p 1159-1185

Submitted: January 12, 2011; Accepted: February 14, 2011 Proofs received from author(s): May 25, 2011 